\title{
Induction of heart failure by minimally invasive aortic constriction in mice: Reduced peroxisome proliferator-activated receptor $\gamma$ coactivator levels and mitochondrial dysfunction
}

\author{
Gloria Faerber, MD, ${ }^{\mathrm{a}}$ Frederico Barreto-Perreia, MS, ${ }^{\mathrm{b}}$ Maria Schoepe, MS, ${ }^{\mathrm{a}}$ Ralf Gilsbach, PhD, \\ Andrea Schrepper, MS, ${ }^{a}$ Michael Schwarzer, PhD, ${ }^{a}$ Friedrich W. Mohr, MD, PhD, ${ }^{a}$ Lutz Hein, MD, PhD, ${ }^{b}$ \\ and Torsten Doenst, $\mathrm{MD}, \mathrm{PhD}^{\mathrm{a}}$
}

\begin{abstract}
Objective: Mitochondrial dysfunction has been suggested as a potential cause for heart failure. Pressure overload is a common cause for heart failure. However, implementing pressure overload in mice is considered a model for compensated hypertrophy but not for heart failure. We assessed the suitability of minimally invasive transverse aortic constriction to induce heart failure in C57BL/6 mice and assessed mitochondrial biogenesis and function.

Methods: Minimally invasive transverse aortic constriction was performed through a ministernotomy without intubation (minimally invasive transverse aortic constriction, $n=68$; sham operation, $n=43$ ). Hypertrophy was assessed based on heart weight/body weight ratios and histologic analyses, and contractile function was assessed based on intracardiac Millar pressure measurements. Expression of selected metabolic genes was assessed with reverse transcription-polymerase chain reaction and Western blotting. Maximal respiratory capacity (state 3) of isolated mitochondria was measured with a Clark-type electrode.
\end{abstract}

Results: Survival was $62 \%$. Within 7 weeks, minimally invasive transverse aortic constriction induced significant hypertrophy (heart weight/body weight ratio: $10.08 \pm 0.28 \mathrm{mg} / \mathrm{g}$ for minimally invasive transverse aortic constriction vs $4.66 \pm 0.07 \mathrm{mg} / \mathrm{g}$ for sham operation; $\mathrm{n}=68 ; P<.01$ ). Fifty-seven percent of mice undergoing minimally invasive transverse aortic constriction displayed signs of heart failure (pleural effusions, dyspnea, weight loss, and dp/dt $\mathrm{dmax}_{\max }$ of $3114 \pm 422 \mathrm{~mm} \mathrm{Hg} / \mathrm{s}, P<.05$ ). All of them had heart weight/body weight ratios of greater than 10. Mice undergoing minimally invasive transverse aortic constriction with heart weight/body weight ratios of less than $10 \mathrm{had}$ normal contractile function (dp/dt $\max _{\max }$ of $6471 \pm 292 \mathrm{~mm} \mathrm{Hg} / \mathrm{s} \mathrm{vs} \mathrm{dp} / \mathrm{dt}_{\max }$ of $6933 \pm 205 \mathrm{mmHg} / \mathrm{s}$ in sham mice) and no clinical signs of heart failure. The mitochondrial coactivator peroxisome proliferator-activated receptor $\gamma$ coactivator alpha (PGC- $1 \alpha$ ) was downregulated in failing hearts only. PGC- $1 \alpha$ and fatty acid oxidation gene expression were also decreased in failing hearts. State 3 respiration of isolated mitochondria was significantly reduced in all hearts subjected to pressure overload.

Conclusions: Contractile dysfunction and heart failure can be induced in wild-type mice by means of minimally invasive aortic constriction. Pressure overload-induced heart failure in mice is associated with mitochondrial dysfunction, as characterized by downregulation of PGC- $1 \alpha$ and reduced oxidative capacity. (J Thorac Cardiovasc Surg 2011;141:492-500)

丹 Supplemental material is available online.

From the Department of Cardiac Surgery, ${ }^{\text {a }}$ University of Leipzig Heart Center, Leipzig, Germany, and the Department of Experimental and Clinical Pharmacology and Toxicology, ${ }^{\mathrm{b}}$ University of Freiburg, Freiburg, Germany.

T.D. is Heisenberg Professor of the Deutsche Forschungsgemeinschaft (DFG) at the University of Leipzig, and the study was supported by grants from the DFG (Do602/4-1, 6-1, 8-1). L.H. and R.G. were supported by the Deutsche Forschungsgemeinschaft (PAK350/1), and G.F. received a grant from the Forschungskommission of the University of Freiburg.

Disclosures: Authors have nothing to disclose with regard to commercial support.

Received for publication Oct 9, 2009; revisions received Feb 22, 2010; accepted for publication March 20, 2010; available ahead of print May 6, 2010.

Address for reprints: Torsten Doenst, MD, PhD, Department of Cardiac Surgery,

University of Leipzig Heart Center, Strümpellstr. 39, 04289 Leipzig, Germany

(E-mail: torsten.doenst@med.uni-leipzig.de).

0022-5223/ $\$ 36.00$

Copyright $\odot 2011$ by The American Association for Thoracic Surgery

doi:10.1016/j.jtcvs.2010.03.029
Pressure overload is one of the most common causes of heart failure. ${ }^{1}$ Increased workload also increases energy demand. Recent evidence suggests an important role of metabolic processes in the development of heart failure. The discussed mechanisms focus on defects located in the mitochondria. Reduced expression of the peroxisome proliferatoractivated receptor (PPAR) $\gamma$ coactivator $1 \alpha(\mathrm{PGC}-1 \alpha)$ during hypertrophy and heart failure in rats has been demonstrated. ${ }^{2,3}$

PGC- $1 \alpha$ and its homologue, PGC- $1 \beta$, are metabolic coactivators governing mitochondrial biogenesis and are key regulators of fatty acid oxidation and oxidative phosphorylation. ${ }^{4}$ For the establishment of a causal relationship between these metabolic alterations and the clinical presentation of heart failure, genetically altered murine models will be essential and have already been generated. ${ }^{2}$ However, testing these genetic variations in models of heart failure results in 2 significant limitations. First, in ischemic heart failure 


$$
\begin{aligned}
& \text { Abbreviations and Acronyms } \\
& \text { ADP = adenosine diphosphate } \\
& \text { ATP = adenosine triphosphate } \\
& \text { BW }=\text { body weight } \\
& \text { HW = heart weight } \\
& \text { MITAC }= \text { minimally invasive transverse aortic } \\
& \text { constriction } \\
& \text { PCR }= \text { polymerase chain reaction } \\
& \text { PGC }= \text { peroxisome proliferator-activated } \\
& \text { receptor } \gamma \text { coactivator } \\
& \text { PPAR }= \text { peroxisome proliferator-activated } \\
& \text { receptor }
\end{aligned}
$$

models the occlusion of the left anterior descending coronary artery results in postinfarct remodeling, a pathomechanism completely different from pressure overload. Second, in the hands of most investigators, pressure overload in wildtype mice induced by transverse aortic constriction results in hypertrophy, although not in heart failure with a contractile dysfunction.

We reasoned that performance of transverse aortic constriction without intubation through a partial median sternotomy might allow for a tighter constriction, potentially leading to heart failure and contractile dysfunction in wildtype mice. We therefore modified a previously reported minimally invasive technique ${ }^{3}$ and assessed its ability to induce heart failure. We also determined the effect on PGC-1 signaling and mitochondrial respiratory capacity. Our results demonstrate that minimally invasive transverse aortic constriction (MITAC) is suitable to induce heart failure with contractile dysfunction, which is associated with a downregulation of PGC- $1 \alpha$ and fatty acid oxidation gene expression, as well as reduced oxidative capacity.

\section{MATERIALS AND METHODS \\ Animals}

Male C57BL/6 mice (22-24 g, 5-6 weeks of age) were obtained from Charles River (Sulzfeld, Germany) and were fed ad libitum at $21^{\circ} \mathrm{C}$ with a light cycle of 12 hours. The use of animals and the experimental protocol were approved by the Animal Welfare Committees of the Universities of Leipzig and Freiburg, Germany.

\section{Minimally Invasive Aortic Constriction}

The procedure of minimally invasive aortic constriction is a modification of 2 previously described techniques. ${ }^{3,5}$ For the banding procedure, mice were anesthetized with a mixture of ketamine $(60-100 \mathrm{mg} / \mathrm{kg}$ body weight [BW] administered intraperitoneally) and xylazine $(5-10 \mathrm{mg} / \mathrm{kg} \mathrm{BW}$ intraperitoneally), and transverse aortic constriction was performed through an upper partial sternotomy $(0.2-0.3 \mathrm{~cm})$ in spontaneously breathing nonintubated mice. Particular care was taken not to touch or damage the parietal pleura to prevent pneumothorax development. The aortic arch was carefully exposed, and a 5-0 polyviolene suture (Harvard Apparatus, Holliston, Mass) was used to tightly constrict the aorta between the brachiocephalic trunk and the left carotid artery over a 29-gauge cannula. After ligation, the cannula was removed to leave an opening not greater than the diameter of the cannula. In mice undergoing sham operations the procedure was identical, with the exception of suture constriction of the aortic arch. Overall mortality was 38\% (42/110) in mice undergoing MITAC and 4\% (2/45) in animals undergoing sham operations.

\section{Assessment of Left Ventricular Function}

After 7 weeks, all mice were anesthetized with isoflurane, and cardiac function was evaluated with a 1.4F Millar microtip catheter inserted into the aorta and the left ventricle through the right carotid artery. ${ }^{6}$ Aortic and intraventricular systolic and diastolic pressures were recorded, and both positive $\left(\mathrm{dp} / \mathrm{dt}_{\max }\right)$ and negative $\left(\mathrm{dp} / \mathrm{dt}_{\min }\right)$ pressure changes over time were obtained. The rate-pressure product was assessed as the product of systolic pressure in the aorta and heart rate (expressed as millimeters of mercury per minute). After invasive measurements, mice were killed by means of cervical dislocation. Hearts were excised for further analyses.

\section{Isolation of Mitochondria}

Tissue homogenization and isolation of mitochondria was carried out as described previously. ${ }^{7}$ For isolation of mitochondria, $500 \mu \mathrm{L}$ of the homogenate was centrifuged at $750 \mathrm{rpm}$ for 10 minutes, and the supernatant was stored in subsarcolemmal mitochondria. The pellet was treated with Nagarse $(5 \mathrm{mg} / \mathrm{g}$ wet weight) for 30 seconds and centrifuged at $7000 \mathrm{rpm}$ for 5 minutes. The resulting pellet was resuspended with KEA (180 $\mathrm{mmol} / \mathrm{L} \mathrm{KCl}, 10 \mathrm{mmol} / \mathrm{L}$ ethylenediamine tetraacetic acid, and $0.5 \%$ albu$\mathrm{min}$ ) and centrifuged at $750 \mathrm{rpm}$ for 10 minutes. The supernatant was transferred to the tube containing SSM and spun down 3 times at $7000 \mathrm{rpm}$ for 10 minutes. The last pellet was diluted with one third KME $(100 \mathrm{mmol} / \mathrm{L} \mathrm{KCl}$, $50 \mathrm{mmol} / \mathrm{L} 3-(\mathrm{N}$-morpholino)propanesulfonic acid, and $0.5 \mathrm{mmol} / \mathrm{L}$ ethyleneglycol-bis-[ $\beta$-aminoethylether]-N,N, $\mathrm{N}^{\prime}, \mathrm{N}^{\prime}$-tetraacetic acid) of used homogenate. All steps were carried out at $4^{\circ} \mathrm{C}$.

\section{Mitochondrial Respiration}

Oxygen consumption of isolated mitochondria was measured at $25^{\circ} \mathrm{C}$ with a Clark-type oxygen electrode fitted to a water-jacketed reaction chamber of $1 \mathrm{~mL}$ in volume. ${ }^{8}$ Mitochondrial preparations were added to respiration medium (100 mmol/L KCl; $50 \mathrm{mmol} / \mathrm{L} 3-(\mathrm{N}$-morpholino)propanesulfonic acid; $1.0 \mathrm{mmol} / \mathrm{L}$ ethyleneglycol-bis-[ $\beta$-aminoethylether]- $\mathrm{N}, \mathrm{N}, \mathrm{N}^{\prime}, \mathrm{N}^{\prime}$-tetraacetic acid; $5.0 \mathrm{mmol} / \mathrm{L}$ kaliumphosphate; and $1.0 \mathrm{mg} / \mathrm{mL}$ defatted bovine serum albumin) to a final concentration of $1 \mathrm{U}$ of citrate synthase per milliliter in the reaction chamber. Maximal oxygen consumption (state 3 respiration), using glutamate, succinate, pyruvate, or palmitoyl-carnitine as a substrate, was stimulated by adding $20 \mu \mathrm{L}$ of adenosine diphosphate (ADP; 10 $\mathrm{mmol} / \mathrm{L}$ ). State 4 respiration was measured as the rate of oxygen consumption after total phosphorylation of added ADP. ${ }^{9}$ Citrate synthase served as a mitochondrial marker enzyme and was assessed by using a conventional enzyme assay, as described previously. ${ }^{10}$

\section{Quantitative Real-Time Reverse Transcription- Polymerase Chain Reaction}

Total RNA from individual murine hearts was isolated with the RNeasy Fibrous Tissue Mini Kit (Qiagen, Hilden, Germany). Quantitative polymerase chain reaction (PCR) was carried out as described previously. ${ }^{11}$ In brief, total RNA ( $1 \mu \mathrm{g}$ per sample) was DNase treated and reverse transcribed according to the manufacturer's instructions (Quantitect Rev. Transcription Kit, Qiagen). For quantitative real-time PCR (Quantitect SyBrGreen Kit, Qiagen), $20 \mathrm{ng}$ of cDNA and $300 \mathrm{nmol} / \mathrm{L}$ sequence-specific primers (MWG, Ebersberg, Germany) were used. Reactions were run in triplicate on a MX3000P detector (Stratagene, Amsterdam, The Netherlands). The cycling conditions were as follows: 15 seconds of polymerase activation at $95^{\circ} \mathrm{C}$ and 40 cycles at $95^{\circ} \mathrm{C}$ for 15 seconds, $58^{\circ} \mathrm{C}$ for 30 seconds, and $72^{\circ} \mathrm{C}$ for 30 seconds. The results were analyzed with MxPro software (Stratagene). Results of the genes of interest were normalized with respect to 
ribosomal S29 mRNA expression. The primers used for quantitative realtime reverse transcription PCR are listed in Table E1.

\section{Western Blots \\ For Western blot analysis, protein concentration of homogenized tissue was measured according to the Bradford method. Protein (maximum of $25 \mathrm{mg}$ ) was loaded in each slot of a $15 \%$ polyacrylamide gel and separated at $120 \mathrm{~mA}$ for 1 hour. Separated proteins were transferred to a polyvinyli- dene fluoride membrane (Millipore, Schwalbach, Germany). Membranes were washed with TBS-T $(0.15 \mathrm{~mol} / \mathrm{L} \mathrm{NaCl}, 0.05 \mathrm{~mol} / \mathrm{L}$ Tris, and $0.1 \%$ Tween) and blocked with 5\% milk for 1 hour at room temperature. Incuba- tion with primary antibody in TBS-T with $5 \%$ bovine serum albumin was done overnight at $4{ }^{\circ} \mathrm{C}$. The primary antibody, OXPHOS Rodent Antibody Cocktail MS604, was purchased from Mito Science (Eugene, Ore) and used at a final dilution of 1:500. The secondary antibody, anti-mouse NXA931, was purchased from GE Healthcare (Fairfield, Conn) and used at a final di- lution of 1:40,000 in TBS-T. In the case of PGC- $1 \alpha$, the primary antibody was purchased from Calbiochem (San Diego, Calif; no. 516557) and used at a final dilution of 1:1000. The secondary antibody, anti-rabbit A6154, was purchased from Sigma-Aldrich (St Louis, Mo) and used at a final dilution of 1:10,000 in TBS-T. Membranes were incubated for 1 hour with secondary antibody at room temperature. After incubation, 6 washing steps of 10 minutes followed. Immunoreactive bands were detected with ECL re- agent (solution A: $100 \mathrm{mmol} / \mathrm{L}$ Tris [pH 8.5], $2.5 \mathrm{mmol} / \mathrm{L}$ luminol, and $0.4 \mathrm{mmol} / \mathrm{L}$ cumaric acid; solution B: $100 \mathrm{mmol} / \mathrm{L}$ Tris $[\mathrm{pH} 8.5]$ and $1.5 \% \mathrm{H}_{2} \mathrm{O}_{2}$ ) and exposed to Hyperfilm (GE Healthcare).}

\section{Histologic Assessment}

For histologic assessment, hearts were fixed with $4 \%$ paraformaldehyde in phosphate-buffered saline, embedded in paraffin, and stained with hematoxylin and eosin. Left ventricular myocyte cross-sectional areas were analyzed by means of computer-assisted morphometry. ${ }^{12}$

\section{Statistical Analysis}

Values are presented as means \pm standard errors of the mean. Data were analyzed by using a 1-way analysis of variance test, followed by post hoc analysis with the Newman-Keuls test.

\section{RESULTS \\ Heart/Body Weight Ratios Correlate With Contractile Function and Markers of Heart Failure}

Table 1 shows heart weight (HW), lung weight, liver weight, body weight (BW), tibia length, and the isolated organ weights and tibia length/BW ratios of mice undergoing sham operations and mice undergoing minimally invasive aortic constriction. All mice with constriction of the aorta had significant hypertrophy (HW/BW ratio: $10.08 \pm 0.28$ $\mathrm{mg} / \mathrm{g}$ for MITAC vs $4.66 \pm 0.07 \mathrm{mg} / \mathrm{g}$ for sham, $P<.01$ ). Fifty-seven percent of these mice had clinical signs of heart failure. All of them had HW/BW ratios of greater than 10 . Mice with suspected heart failure showed lower levels of spontaneous locomotor activity, dyspnea, and rough fur. The onset of heart failure was associated with dramatic increases in lung weight and lung weight/BW ratios. Figure 1, $B$, shows the relationship between $\mathrm{HW} / \mathrm{BW}$ ratios and lung weight. At an HW/BW ratio of greater than 10, there is an abrupt and consistent increase in lung weight. After opening the thorax for organ harvesting, all animals with these symptoms had significant pleural effusions. These
TABLE 1. Heart, lung, liver, and body weights and tibia lengths, as well as the respective ratios from mice undergoing sham operations and from mice 7 weeks after minimally invasive transverse aortic constriction

\begin{tabular}{lccc}
\hline & $\begin{array}{c}\text { Sham group } \\
(\mathbf{n}=\mathbf{4 3})\end{array}$ & $\begin{array}{c}\text { Hypertrophy } \\
\text { group }(\mathbf{n}=\mathbf{2 9})\end{array}$ & $\begin{array}{c}\text { Heart failure } \\
\text { group }(\mathbf{n}=\mathbf{3 9})\end{array}$ \\
\hline Body weight & $25.7 \pm 0.45$ & $27.3 \pm 0.38 \dagger$ & $21.9 \pm 1.4 \dagger, \S$ \\
Heart weight & $119 \pm 2.08$ & $207 \pm 6.2 \dagger$ & $273 \pm 5.34 \dagger, \S$ \\
Heart/body weight & $4.66 \pm 0.07$ & $7.59 \pm 0.2 \dagger$ & $12.6 \pm 0.26 \dagger, \S$ \\
Ventricle weight & $111 \pm 2.53$ & $194 \pm 7.17 \dagger$ & $231 \pm 6.26 \dagger, \S$ \\
Ventricle/body weight & $4.38 \pm 0.06$ & $7.13 \pm 022 \dagger$ & $10.9 \pm 0.46 \dagger, \S$ \\
Lung weight & $138 \pm 4.24$ & $189 \pm 16.7^{*}$ & $433 \pm 19.5 \dagger, \S$ \\
Lung/body weight & $5.55 \pm 0.19$ & $6.94 \pm 0.58^{*}$ & $19.7 \pm 0.8 \dagger, \S$ \\
Liver weight & $1176 \pm 37.2$ & $1248 \pm 27.8$ & $917 \pm 32 \dagger, \S$ \\
Liver/body weight & $47 \pm 1.24$ & $45.8 \pm 0.75$ & $41.5 \pm 1.28 \dagger, \S$ \\
Tibia length & $18 \pm 0.05$ & $18.3 \pm 0.06 \dagger$ & $18 \pm 0.11 \dagger$ \\
Tibia/body weight & $0.7 \pm 0.01$ & $0.66 \pm 0.01$ & $0.84 \pm 0.03 \dagger, \S$ \\
\hline
\end{tabular}

Values are means \pm standard errors of the mean. $* P<.05$ and $\dagger P<.01$ versus the sham group. $\ddagger P<.05$ and $\S P<.01$ versus the hypertrophy group. Mice undergoing minimally invasive transverse aortic constriction were separated into a hypertrophy group and a heart failure group based on their heart weight/body weight ratios (see text for details)

signs were practically absent in animals with $\mathrm{HW} / \mathrm{BW}$ ratios of less than 10. We used these observations to separate the MITAC mice into 2 groups, those with compensated hypertrophy $(\mathrm{HW} / \mathrm{BW}$ ratio $<10)$ and those with heart failure (mice undergoing MITAC with HW/BW ratios $>10$ ).

Figure $1, A$, shows representative histologic stains of myocardial cross-sections from hearts of animals undergoing sham operations or from animals having undergone MITAC having either compensated hypertrophy or heart failure. Hearts with compensated hypertrophy were mainly characterized by increased cardiac mass caused by an increase in wall thickness. Hearts having hypertrophy with failure also displayed increased mass, but wall thickness was less than in the compensated group, and the left ventricular cavity was dilated. Figure $1, C$ and $D$, shows the expression of commonly accepted heart failure marker genes in heart tissue from animals undergoing sham operations or animals undergoing MITAC having hypertrophy with normal contractile function or heart failure. Although atrial natriuretic peptide, brain natriuretic peptide, and $\beta$-isoform of the myosin heavy chain levels were only mildly increased in the hypertrophy group, the values were dramatically increased when clinical signs of heart failure were present. The expression of calcium adenosine triphosphatase of the sarcoplasmic reticulum II was already reduced in the hypertrophied hearts, but the greatest reduction in expression was found in failing hearts.

Table 2 shows the results of the invasive pressure measurements by using the Millar catheter. Heart rate was lowest in the heart failure group. Hypertrophied hearts generated the highest blood pressure, whereas diastolic blood pressures were similar in all groups. Hypertrophied hearts with 


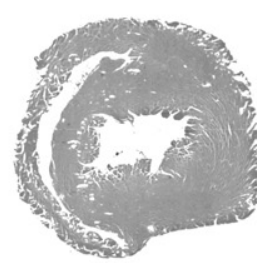

A

Sham

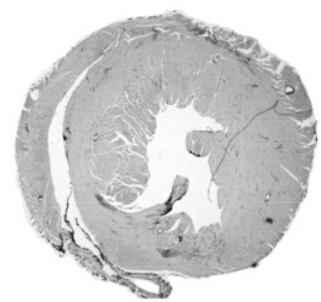

Hypertrophy

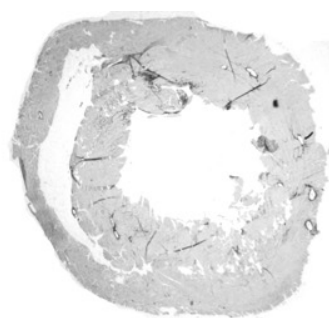

Heart failure
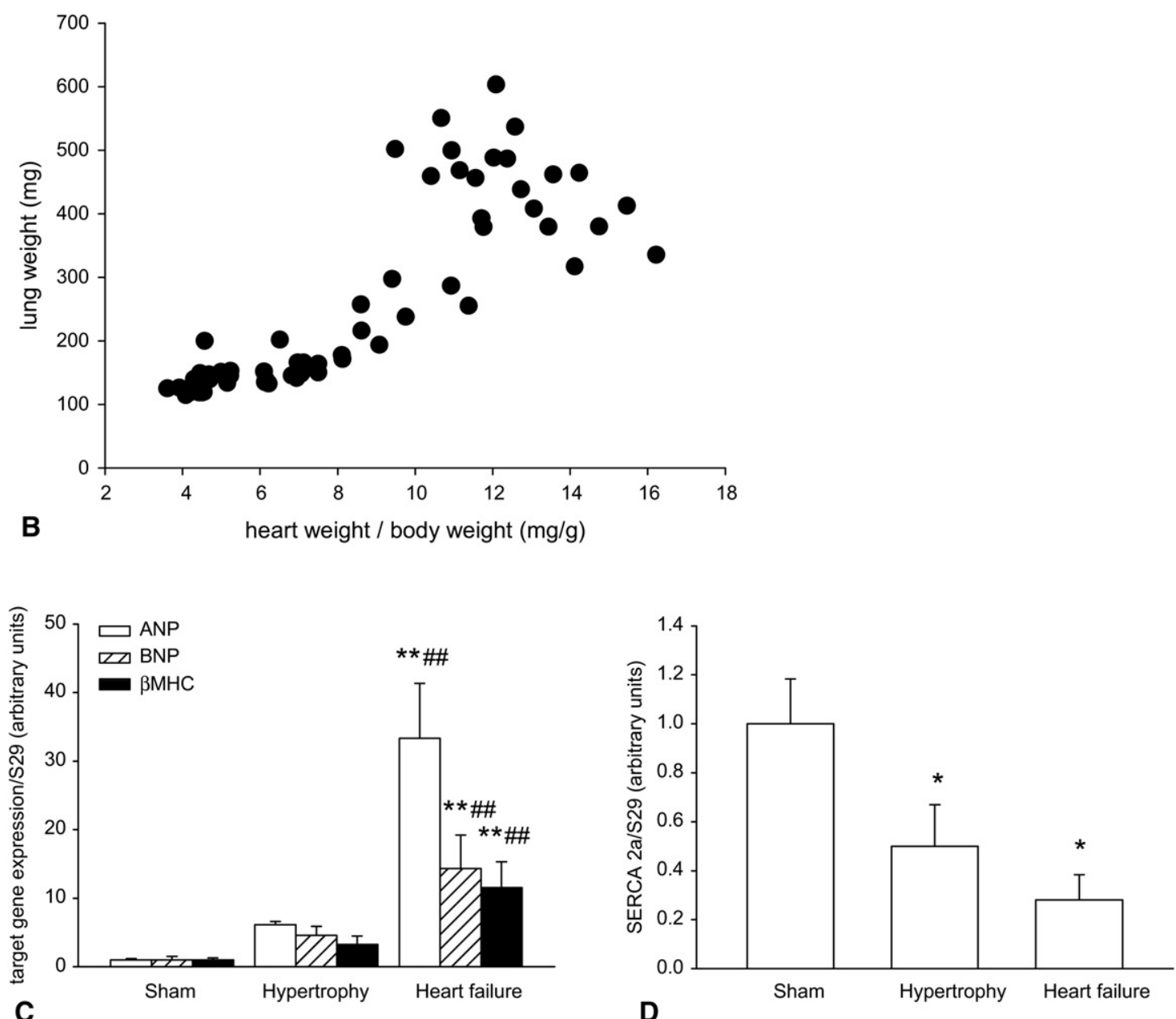

FIGURE 1. A, Histologic stains of representative hearts from animals undergoing sham operations (left image) or from animals undergoing minimally invasive transverse aortic constriction with either compensated hypertrophy (middle image) or heart failure (right image). B, Lung weight as a function of heart/ body weight ratio. $\mathrm{C}$ and $\mathrm{D}$, Expression of heart failure markers in heart tissue from animals undergoing sham operations or animals undergoing minimally invasive transverse aortic constriction having hypertrophy with normal contractile function or heart failure. $\mathrm{C}$, Atrial natriuretic peptide (ANP), brain natriuretic peptide $(B N P), \beta$-isoform of the myosin heavy chain $(\beta-M H C ; \mathrm{n}=5$ per group). $\mathrm{D}$, Calcium adenosine triphosphatase of the sarcoplasmic reticulum II (SERCA $2 a ; \mathrm{n}=5$ per group). $* P<.05$ and $* * P<.01$ versus the sham group. $\# P<.05$ and $\# \# P<.01$ versus the hypertrophy group.

HW/BW ratios between 5 and 10 did not show any evidence of contractile dysfunction. The rate-pressure product was significantly increased, and $\mathrm{dp} / \mathrm{dt}_{\max }$ and $\mathrm{dp} / \mathrm{dt}_{\min }$ values were normal. In the heart failure group the rate-pressure product, $\mathrm{dp} / \mathrm{dt}_{\max }$, and $\mathrm{dp} / \mathrm{dt}_{\min }$ were significantly reduced, indicating the presence of contractile dysfunction.

\section{Respiratory Capacity Is Impaired in Isolated} Mitochondria From Hypertrophied and Failing Hearts

Figure 2 shows the results of the respiratory capacity assessment of isolated mitochondria with a Clark-type electrode. Four different substrates were used to assess the 
TABLE 2. Assessment of contractile function by means of Millar catheter measurement in hypertrophied, failing, and control hearts (sham operations) after minimally invasive transverse aortic constriction

\begin{tabular}{|c|c|c|c|}
\hline & Sham group & $\begin{array}{c}\text { Hypertrophy } \\
\text { group }\end{array}$ & $\begin{array}{l}\text { Heart failure } \\
\text { group }\end{array}$ \\
\hline Heart rate (beats/min) & $566 \pm 15$ & $543 \pm 29$ & $423 \pm 43^{*}, \ddagger$ \\
\hline $\begin{array}{l}\text { Systolic blood } \\
\text { pressure }(\mathrm{mm} \mathrm{Hg})\end{array}$ & $96 \pm 2$ & $144 \pm 7 \dagger$ & $105 \pm 11 \S$ \\
\hline $\begin{array}{l}\text { Diastolic blood } \\
\text { pressure }(\mathrm{mm} \mathrm{Hg})\end{array}$ & $57 \pm 3$ & $63 \pm 2$ & $61 \pm 7$ \\
\hline $\mathrm{dp} / \mathrm{dt}_{\max }(\mathrm{mm} \mathrm{Hg} / \mathrm{s})$ & $6933 \pm 205$ & $6339 \pm 301$ & $3114 \pm 422 \dagger, \S$ \\
\hline $\mathrm{dp} / \mathrm{dt}_{\min }(\mathrm{mm} \mathrm{Hg} / \mathrm{s})$ & $-6498 \pm 232$ & $-6433 \pm 412$ & $-2263 \pm 703 \dagger, \S$ \\
\hline Rate-pressure product & $53,977 \pm 1496$ & $74,553 \pm 3280 \dagger$ & $44,377 \pm 6228 \S$ \\
\hline
\end{tabular}

maximal respiratory capacity based on the generation of reducing equivalents through the glucose oxidation pathway (pyruvate), the fatty acid oxidation pathway (palmitoylcarnitine), or parts of the citric acid cycle (glutamate and succinate). There was a significant reduction in respiratory capacity of mitochondria from both hypertrophied and failing hearts compared with that seen in hearts undergoing sham operations with all substrates. Total activity with succinate (delivering mainly flavin adenine dinucleotide reduced) was 4-fold greater than with glutamate as substrate (delivering mainly $\beta$-nicotinamide adenine dinucleotide). Maximal total activity with the glucose and fatty acid oxidative substrates palmitoyl-carnitine and pyruvate (resulting in a mix of $\beta$-nicotinamide adenine dinucleotide and flavin adenine dinucleotide reduced delivery to the respiratory chain) was more than with glutamate but less than with succinate as substrates.

Assessing respiratory capacity in isolated mitochondria also provides information on the coupling of adenosine triphosphate (ATP) production to oxygen consumption. Table E2 shows the ADP per oxygen ratios of the 3 groups for the 4 substrates used. Although the ADP per oxygen ratios were greater than 2 in the animals undergoing sham operations for all substrates, pressure overload caused an almost uniform significant reduction in this coupling ratio, indicating a loss of efficiency in ATP production not only in the failing hearts but also already in clinically compensated hypertrophy.

\section{PGC-1 $\alpha$ Expression and Downstream Targets Are Reduced in Pressure Overload-Induced Heart Failure}

The top panel of Figure 3 shows the expression of the 2 metabolic coactivators PGC- $1 \alpha$ and PGC- $1 \beta$. Although in the hypertrophy group expression levels were normal, PGC- $1 \alpha$ expression (both mRNA and protein) was significantly reduced in the failing hearts.

The bottom panel of Figure 3 shows the expression of downstream targets of PGC- $1 \alpha$ and PGC- $1 \beta$ (ie, the nuclear transcription factor PPAR $\alpha$ ), genes of the fatty acid oxidation machinery (cluster of differentiation 36 [CD36], carnitine O-palmitoyltransferase $1[C P T 1]$, long-chain acyl coenzype A dehydrogenase $[L C A D]$, and medium chain acyl CoA dehydrogenase $[M C A D])$. There was a trend toward reduced expression of the fatty acid oxidation machinery in mice undergoing MITAC, which was consistent with an early significant reduction in the expression of its transcription factor, PPAR $\alpha$. Assessment of $C d k 9$ expression, a recently described potential suppressor of PGC- $1 \alpha,{ }^{13}$ revealed an unexpected downregulation in the heart failure group.

Gene and protein expression of the respiratory chain complexes (I-V) are shown in Table E3. The expression of the complexes did not show a clear trend. Complex I expression was lowest in mice with hypertrophy and heart failure, but the differences were only significantly lower for protein expression in the hypertrophy group. Complexes III, IV, and $\mathrm{V}$ had normal mRNA but reduced protein expression in the heart failure group compared with those seen in control mice.

\section{DISCUSSION}

We demonstrate in this study that MITAC is able to induce heart failure in wild-type mice. As expected, this pressure overload-induced heart failure is associated with a downregulation of PGC- $1 \alpha$ and fatty acid oxidation gene expression and reduced oxidative capacity.

The novel observation in this study is the inducibility of heart failure by MITAC in a wild-type mouse. Our ability to induce heart failure with pressure overload in wild-type mice allowed us to assess the relevance of commonly discussed metabolic pathomechanisms for the onset of pressure overload-induced heart failure. Although our findings are in general consistent with the common notions, some of our observations do not completely fulfill the expectations and require further discussion.

One suggested metabolic mechanism for the development of heart failure is a maladaptive downregulation of PGC- $1 \alpha .^{3}$ If PGC- $1 \alpha$, the coactivator and therefore regulator of the transcription factors for respiratory chain and fatty acid oxidation gene expression, ${ }^{14}$ is downregulated, it is easily envisioned that the ability to produce ATP is decreased. We find less PGC- $1 \alpha$ and less fatty acid oxidation gene expression, but the expression of both respiratory chain mRNA and protein is not uniformly decreased in the failing hearts. In addition, in the hypertrophied hearts with normal function, in which PGC- $1 \alpha$ expression is normal, there is evidence for mitochondrial dysfunction and a significant downregulation of PPAR $\alpha$ (the key transcription factor for fatty acid oxida$\operatorname{tion}^{15}$ ). These observations are not fully consistent with the hypothesis that PGC- $\alpha$ is the cause for these alterations. PGC- $\alpha$ might therefore not be the only culprit, and other regulatory mechanisms might be additionally involved. The 

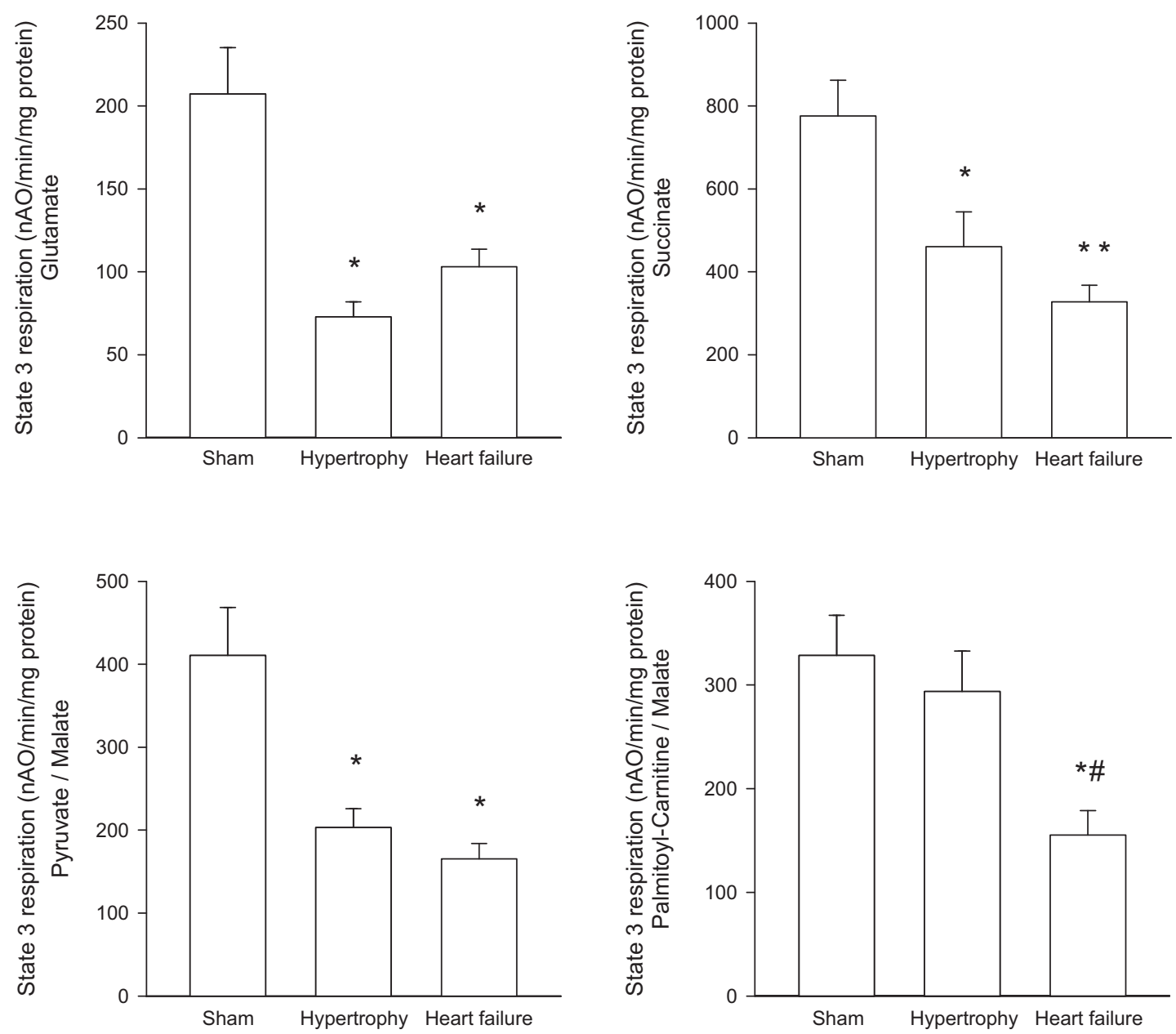

FIGURE 2. State 3 respiration of isolated mitochondria from animals undergoing sham operations and animals undergoing minimally invasive transverse aortic constriction having hypertrophy with normal contractile function or heart failure separated by the heart/body weight ratio $(\mathrm{n}=4-12)$. $* P<.05$ and $* * P<.01$ versus the sham group. $\# P<.05$ and $\# \# P<.01$ versus the hypertrophy group.

reduced respiratory capacity of isolated mitochondria from hypertrophied and failing hearts at almost normal protein levels might suggest that the regulation of the respiratory complexes could be defective and not merely the expression of the machinery. A recent investigation in dogs with microembolization-induced heart failure demonstrated defects in the formation of respiratory supercomplexes, explaining mitochondrial dysfunction at normal protein expression. ${ }^{16}$ Whether this mechanism also accounts for our findings remains to be determined.

Nevertheless, the in vitro assessment of state 3 respiration allows the identification of potential sites of dysregulation. We found decreased state 3 respiration in cases of both hypertrophy and heart failure with all substrates. This finding supports the notion that a reduction in ATP-producing capacity might be a cause for the onset of heart failure. ${ }^{17}$ Taking a close look at the total activities achieved with the different substrates might help to identify the rate-limiting steps. Total respiratory capacity in animals undergoing sham operations with glutamate as a substrate resulted in a value of around 350 nanoatoms of oxygen per milligram of protein. The same value with succinate as a substrate was 4 times greater, suggesting a lower catalytic capacity of complex I compared with the downstream complexes in the chain. The effects of the banding procedure affected all substrates similarly, and the lowest values were again found with glutamate as a substrate. The reduced values in hypertrophied and failing hearts with succinate were similar to the sham values with glutamate as a substrate, suggesting that if a reduction in respiratory capacity is responsible for the onset of heart failure, the rate-limiting step, and therefore the potential culprit, might be found at the level of complex I. This conclusion would be consistent with our findings in rats in which we identified a specific complex I defect as a potential cause of decreased respiratory capacity (unpublished observations, 2009). 

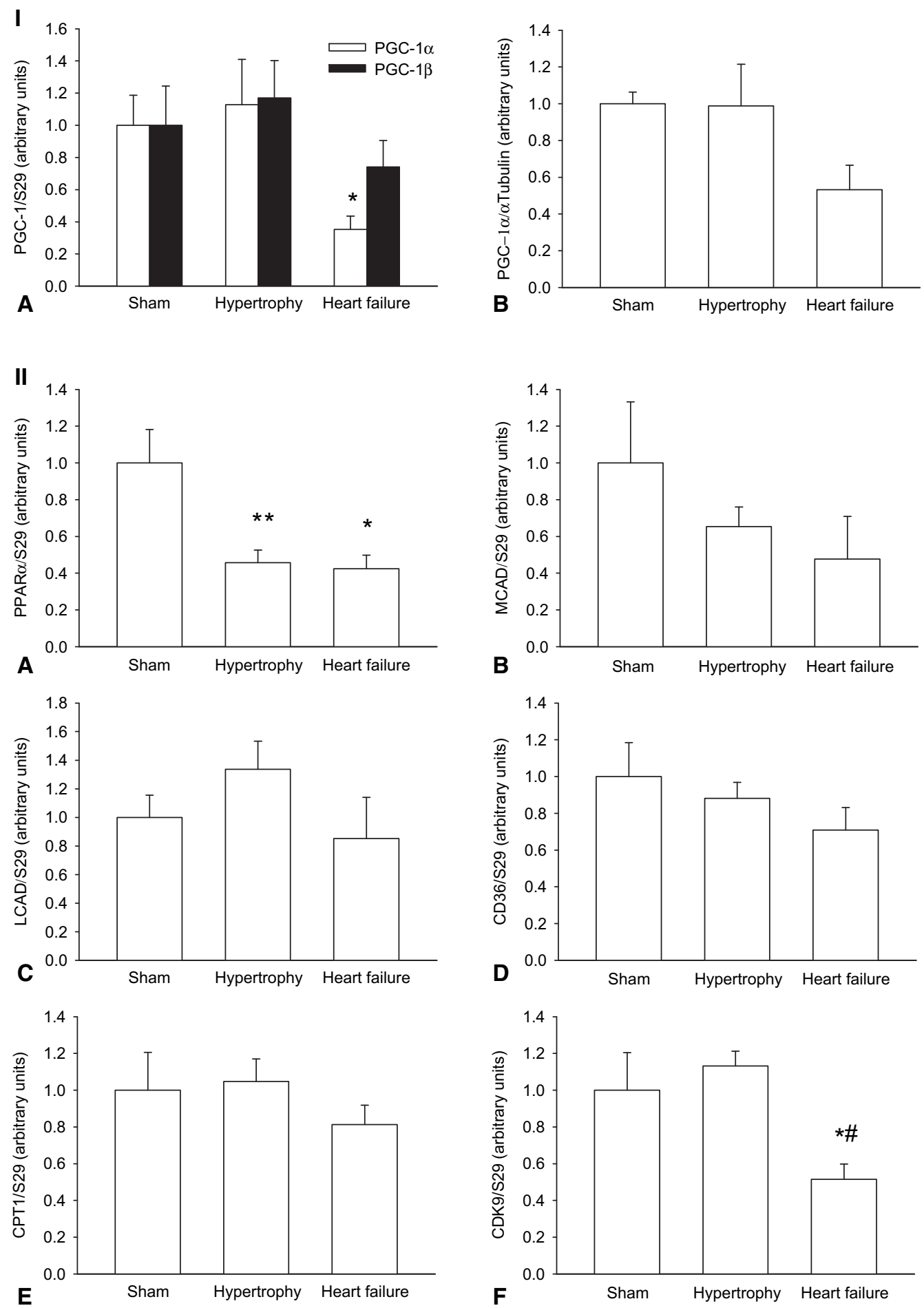

FIGURE 3. Top panels, $\mathrm{mRNA}(\mathrm{n}=5$ per group; $\mathrm{A})$ and protein expression $(\mathrm{n}=10-12$ per group; $\mathrm{B})$ of PGC- $1 \alpha$ and PGC- $1 \beta$ in cardiac tissue from animals undergoing sham operations and animals undergoing minimally invasive transverse aortic constriction having hypertrophy with normal contractile function or heart failure separated by the heart/body weight ratio. $S 29 / \alpha$-tubulin was used as a housekeeping gene/protein after stable expression under current conditions was established. Bottom panels, mRNA expression of downstream targets of PGC- $1 \alpha$. Genes involved in fatty acid oxidation: PPARA (A), MCAD (B) and $L C A D(\mathrm{C}), C D 36$ (D), CPT1 (E), and the upstream PGC-1 $\alpha$ regulator $C D K 9(\mathrm{~F})$ in cardiac tissue from animals undergoing sham operations and animals undergoing minimally invasive transverse aortic constriction having hypertrophy with normal contractile function or heart failure separated by the heart/ body weight ratio. $S 29$ was used as housekeeping gene after stable expression of this gene under the current conditions was established ( $\mathrm{n}=5$ per group). $* P<.05$ and $* * P<.01$ versus the sham group. $\# P<.05$ and $\# \# P<.01$ versus the hypertrophy group. 
Although our findings are not fully consistent with the above-mentioned PGC- $1 \alpha$ hypothesis, they provide substantial support for it and do not reject it. Others have already demonstrated in PGC- $1 \alpha$-null mice with heart failure on aortic constriction that reintroduction of the PGC- $1 \alpha$ construct and re-expressing it resulted in a delay in the onset of contractile dysfunction. ${ }^{2}$ Although the authors thereby demonstrated the pharmacologic potential of PGC-1 overexpression, the causal link between PGC- $1 \alpha$ downregulation and the onset of heart failure has not yet been established. Overexpression of PGC- $1 \alpha$ in mice not undergoing aortic constriction results in heart failure, possibly through the massive amounts of $\mathrm{PGC}-1 \alpha$ protein present in these hearts. ${ }^{14}$ The effects of overexpressing PGC- $1 \alpha$ in mice with heart failure is currently under investigation.

The finding of impaired mitochondrial function in the face of contractile dysfunction has led to the speculation of a potential causal relationship between the two. The first metabolic derangement that was identified in heart failure was a downregulation of fatty acid oxidation gene expression. ${ }^{18}$ Our results support this notion, suggesting that the impairment of mitochondrial function (ie, ATP-producing capacity) is unable to support the increased energy demand by the hypertrophied contractile apparatus and increased work load. It is interesting to note in this context that many pathological signaling pathways activate hypertrophic growth but inhibit mitochondrial biogenesis. ${ }^{19}$ We believe that a balance between hypertrophic growth and mitochondrial function is required for physiological hypertrophy and that heart failure ensues once a dysbalance arises. This hypothesis is supported by the findings of contractile dysfunction in animal models with overexpression of either activators of mitochondrial biogenesis ${ }^{20}$ or stimulators of hypertrophic growth ${ }^{21}$ and is currently the mainstay of our experimental work.

This report is the first to demonstrate the reproducible induction of heart failure by minimally invasive induction of pressure overload. Previous investigations describe models in which pressure overload only causes hypertrophy $^{3}$ or in which intubation was required. ${ }^{22}$ Rothermel and colleagues ${ }^{23}$ describe a method to induce contractile dysfunction in mice with conventional transverse aortic constriction. In this report the authors tie a suture over a 28 gauge needle. However, the mortality rate was $52 \%$ within the first week. We modified a previously described minimally invasive technique by using a woven suture rather than a monofilament suture and tied over a 29 -gauge instead of a 27 -gauge cannula. We achieved $62 \%$ survival over 7 weeks. Although we did not aim to compare our MITAC approach with conventional transverse aortic constriction, it might be reasoned that the lower surgical mortality in our approach excludes significant disadvantages of the minimally invasive exposure.

Another investigation reported evidence for contractile dysfunction in mice with aortic constriction. ${ }^{24}$ These investigators applied a much thinner monofilament suture to the aortic arch in intubated mice and experienced a striking phenomenon in some of their animals. The suture was internalized into the aortic arch without interruption of aortic continuity leaving the animals free of signs from pressure overload. ${ }^{25}$ In our hands all animals had hypertrophy, and more than half of them had heart failure.

We identified the HW/BW ratio together with increased lung weights as simple but effective markers to distinguish between the mice with compensated hypertrophy and heart failure. In addition, this by default postmortem observation correlates relatively well with the clinical presentation of the mice. Those with heart failure can easily be identified by means of observation of the BW and the activity and breathing patterns in the cage. The mice with heart failure begin to lose weight at the end of the observation period of 7 weeks, whereas the others continue to grow. This finding is subtle by looking at the BWs in Table 1 but is easily visible looking at the individual weight records for each mouse. Thus our method of minimally invasive aortic constriction reproducibly induces heart failure in a significant fraction of mice that can be identified by means of simple in vivo and postmortem parameters.

As a limitation to our study, we were not able to measure pressure gradients across the constricted aorta. Especially in animals with severe heart failure, a prolonged measurement was not possible because of their poor clinical condition. It would be interesting to assess cardiac function in vivo with echocardiographic analysis in the future.

In conclusion, we demonstrate in this study that MITAC can be applied to induce heart failure with contractile dysfunction in wild-type mice. This pressure overload-induced heart failure is associated with a downregulation of PGC$1 \alpha$ and fatty acid oxidation gene expression and reduced oxidative capacity.

\section{References}

1. He J, Ogden LG, Bazzano LA, Vupputuri S, Loria C, Whelton PK. Risk factors for congestive heart failure in US men and women: NHANES I epidemiologic follow-up study. Arch Intern Med. 2001;161:996-1002.

2. Arany Z, Novikov M, Chin S, Ma Y, Rosenzweig A, Spiegelman BM. Transverse aortic constriction leads to accelerated heart failure in mice lacking PPAR-gamma coactivator 1alpha. Proc Natl Acad Sci U S A. 2006;103:10086-91.

3. Hu P, Zhang D, Swenson L, Chakrabarti G, Abel ED, Litwin SE. Minimally invasive aortic banding in mice: effects of altered cardiomyocyte insulin signaling during pressure overload. Am J Physiol Heart Circ Physiol. 2003;285:H1261-9.

4. Wu Z, Puigserver P, Andersson U, Zhang C, Adelmant G, Mootha V, et al. Mechanisms controlling mitochondrial biogenesis and respiration through the thermogenic coactivator PGC-1. Cell. 1999;98:115-24.

5. Rockman HA, Ross RS, Harris AN, Knowlton KU, Steinhelper ME, Field LJ, et al. Segregation of atrial-specific and inducible expression of an atrial natriuretic factor transgene in an in vivo murine model of cardiac hypertrophy. Proc Natl Acad Sci U S A. 1991;88:8277-81.

6. Brede M, Wiesmann F, Jahns R, Hadamek K, Arnolt C, Neubauer S, et al. Feedback inhibition of catecholamine release by two different alpha2-adrenoceptor subtypes prevents progression of heart failure. Circulation. 2002;106:2491-6.

7. Bugger H, Chemnitius JM, Doenst T. Differential changes in respiratory capacity and ischemia tolerance of isolated mitochondria from atrophied and hypertrophied hearts. Metabolism. 2006;55:1097-106. 
8. Chance B, Williams GR. The respiratory chain and oxidative phosphorylation. Adv Enzymol. 1956;17:65-154.

9. Chemnitius JM, Manglitz T, Kloeppel M, Doenst T, Schwartz P, Kreuzer H, et al. Rapid preparation of subsarcolemmal and interfibrillar mitochondrial subpopulations from cardiac muscle. Int J Biochem. 1993;25:589-96.

10. Srere PA. Citrate synthase. Methods Enzymol. 1969;13:3-11.

11. Gilsbach R, Kouta M, Bonisch H, Bruss M. Comparison of in vitro and in vivo reference genes for internal standardization of real-time PCR data. Biotechniques. 2006;40:173-7.

12. Gilsbach R, Brede M, Beetz N, Moura E, Muthig V, Gerstner C, et al. Heterozygous alpha 2C-adrenoceptor-deficient mice develop heart failure after transverse aortic constriction. Cardiovasc Res. 2007;75:728-37.

13. Sano M, Wang SC, Shirai M, Scaglia F, Xie M, Sakai S, et al. Activation of cardiac Cdk9 represses PGC-1 and confers a predisposition to heart failure. EMBO J. 2004;23:3559-69.

14. Russell LK, Mansfield CM, Lehman JJ, Kovacs A, Courtois M, Saffitz JE, et al. Cardiac-specific induction of the transcriptional coactivator peroxisome proliferator-activated receptor gamma coactivator-1 alpha promotes mitochondrial biogenesis and reversible cardiomyopathy in a developmental stage-dependent manner. Circ Res. 2004;94:525-33.

15. Barger PM, Browning AC, Garner AN, Kelly DP. p38 mitogen-activated protein kinase activates peroxisome proliferator-activated receptor alpha: a potential role in the cardiac metabolic stress response. J Biol Chem. 2001;276:44495-501.

16. Rosca MG, Vazquez EJ, Kerner J, Parland W, Chandler MP, Stanley W, et al. Cardiac mitochondria in heart failure: decrease in respirasomes and oxidative phosphorylation. Cardiovasc Res. 2008;80:30-9.
17. Taha M, Lopaschuk GD. Alterations in energy metabolism in cardiomyopathies. Ann Med. 2007;39:594-607.

18. Sack MN, Rader TA, Park S, Bastin J, McCune SA, Kelly DP. Fatty acid oxidation enzyme gene expression is downregulated in the failing heart. Circulation. 1996;94:2837-42.

19. Ni YG, Berenji K, Wang N, Oh M, Sachan N, Dey A, et al. Foxo transcription factors blunt cardiac hypertrophy by inhibiting calcineurin signaling. Circulation. 2006;114:1159-68.

20. Huss JM, Kelly DP. Mitochondrial energy metabolism in heart failure: a question of balance. J Clin Invest. 2005;115:547-55.

21. Heineke J, Molkentin JD. Regulation of cardiac hypertrophy by intracellular signalling pathways. Nat Rev Mol Cell Biol. 2006;7:589-600.

22. Rockman HA, Knowlton KU, Ross J Jr, Chien KR. In vivo murine cardiac hypertrophy. A novel model to identify genetic signaling mechanisms that activate an adaptive physiological response. Circulation. 1993;87(suppl VII): VII14-21.

23. Rothermel BA, Berenji K, Tannous P, Kutschke W, Dey A, Nolan B, et al. Differential activation of stress-response signaling in load-induced cardiac hypertrophy and failure. Physiol Genomics. 2005;23:18-27.

24. Lygate CA, Fischer A, Sebag-Montefiore L, Wallis J, ten Hove M, Neubauer S. The creatine kinase energy transport system in the failing mouse heart. $J \mathrm{Mol}$ Cell Cardiol. 2007;42:1129-36.

25. Lygate CA, Schneider JE, Hulbert K, ten Hove M, Sebag-Montefiore LM, Cassidy PJ, et al. Serial high resolution 3D-MRI after aortic banding in mice: band internalization is a source of variability in the hypertrophic response. Basic Res Cardiol. 2006;101:8-16. 
TABLE E1. Primer and probe sequences and accession numbers of genes used for quantification of mRNA levels by means of real-time reverse transcription-polymerase chain reaction

\begin{tabular}{|c|c|c|}
\hline Gene & Forward/reverse primer sequence & \\
\hline Nppa & $\begin{array}{r}\text { GCTTCCAGGCCATATTGGAG/ } \\
\text { GGGGGCATGACCTCATCTT }\end{array}$ & NM_008725.2 \\
\hline$N p p b$ & $\begin{array}{l}\text { CCCAAAAAGAGTCCTTCGGTC/ } \\
\text { CGGTCTATCTTGTGCCCAAAG }\end{array}$ & NM_008726.3 \\
\hline Myh7 & $\begin{array}{l}\text { ACTGTCAACACTAAGAGGGTCA/ } \\
\text { TTGGATGATTTGATCTTCCAGGG }\end{array}$ & NM_080728.2 \\
\hline Atp2a2 & $\begin{array}{l}\text { GAGAACGCTCACACAAAGACC/ } \\
\text { CTTCTTCAGCCGGCAATTCGTTG }\end{array}$ & NM_009722.2 \\
\hline Ppargc la & $\begin{array}{l}\text { GAAAGGGCCAAACAGAGAGA/ } \\
\text { GTAAATCACACGGCGCTCTT }\end{array}$ & NM_008904.1 \\
\hline Ppargc $1 b$ & $\begin{array}{l}\text { TTCCTCAACTATCTCTCTGACACG/ } \\
\text { TCTGGCAAGTCAGCACACA }\end{array}$ & NM_133249 \\
\hline Ppara & $\begin{array}{l}\text { CCGAGGGCTCTGTCATCA/ } \\
\text { GGGCAGCTGACTGAGGAA }\end{array}$ & NM_011144 \\
\hline Acadm & $\begin{array}{l}\text { CTGATGAGGGACGCCAAG/ } \\
\text { TCAATGTGCTCACGAGCTATG }\end{array}$ & U07159 \\
\hline Acadl & $\begin{array}{l}\text { TGGTGGGGACTTGCTCTC/ } \\
\text { GTGCAATTGGAGTACGCTTG }\end{array}$ & U21489 \\
\hline$C d 36$ & $\begin{array}{c}\text { TGAAAAGTCTCGGACATTGAGA/ } \\
\text { CAGATCCGAACACAGCGTAG }\end{array}$ & NM_007643 \\
\hline$C p t 1 b$ & $\begin{array}{l}\text { CGTCACTGCCTAAGCTTCCT/ } \\
\text { CCGCACAGAATCCAAGTACC }\end{array}$ & NM_009948 \\
\hline$C D K 9$ & $\begin{array}{l}\text { AAGCCAAGCACCGTCAGA/ } \\
\text { AGGCTGTGATGGGGAACC }\end{array}$ & NM_130860 \\
\hline Ndufal2 & $\begin{array}{l}\text { TGGTGGAGGTCCTGAAGC/ } \\
\text { CCCACCAGTGTACCAATCCT }\end{array}$ & ВC086922 \\
\hline$S d h b$ & $\begin{array}{l}\text { GGAGGGCAAGCAACAGTATC/ } \\
\text { ACTCGTACAGCCCGTCCA }\end{array}$ & ВС051934.1 \\
\hline Uqcrc2 & $\begin{array}{l}\text { AAGGCATTCGGAGTGATATTG/ } \\
\text { AACTCGGGTGCTGTGGTG }\end{array}$ & NM_025899 \\
\hline Cox $5 a$ & $\begin{array}{l}\text { TTAAATGAATTGGGAATCTCCAC/ } \\
\text { GTCCTTAGGAAGCCCATCG }\end{array}$ & NM_007747 \\
\hline Atp5b & $\begin{array}{l}\text { GCCAAGATGTCCTGCTGTTTA/ } \\
\text { CCCAATAAGGCAGACACCTC }\end{array}$ & ВC037127 \\
\hline Rps29 & $\begin{array}{l}\text { ATGGGTCACCAGCAGCTCTA/ } \\
\text { AGCCTATGTCCTTCGCGTACT }\end{array}$ & NM_0099093.1 \\
\hline
\end{tabular}

TABLE E2. ADP/O ratios of isolated cardiac mitochondria in animals undergoing sham operations and animals undergoing minimally invasive transverse aortic constriction having hypertrophy with normal contractile function or heart failure

\begin{tabular}{lccc}
\hline & & ADP/O & \\
\cline { 3 - 3 } Respiratory substrate & Sham & $\begin{array}{c}\text { Hypertrophy } \\
\text { group }\end{array}$ & $\begin{array}{c}\text { Heart failure } \\
\text { group }\end{array}$ \\
\hline Glutamate & $2.03 \pm 0.12$ & $1.32 \pm 0.10 \dagger$ & $1.60 \pm 0.06^{*}$ \\
Succinate & $2.27 \pm 0.19$ & $1.65 \pm 0.21^{*}$ & $1.59 \pm 0.16^{*}$ \\
Palmitoyl-carnitine/malate & $2.11 \pm 0.13$ & $1.56 \pm 0.33$ & $1.31 \pm 0.16 \dagger$ \\
Pyruvate/malate & $2.33 \pm 0.11$ & $2.58 \pm 0.54$ & $1.93 \pm 0.19$ \\
\hline Values are means \pm standard errors of the mean $\left(\mathrm{n}=4-12\right.$ per group). ${ }^{*} P<.05$ and
\end{tabular}

$\dagger P<.01$ versus the sham group.
TABLE E3. mRNA and protein expression of the respiratory chain complexes $I$ to $V$ from animal undergoing sham operations and animals undergoing minimally invasive transverse aortic constriction having hypertrophy with normal contractile function or heart failure

\begin{tabular}{lccc}
\hline Expression & $\begin{array}{c}\text { Sham } \\
\text { group }\end{array}$ & $\begin{array}{c}\text { Hypertrophy } \\
\text { group }\end{array}$ & $\begin{array}{c}\text { Heart failure } \\
\text { group }\end{array}$ \\
\hline mRNA & & & \\
Complex I & $1 \pm 0.55$ & $0.49 \pm 0.07$ & $0.35 \pm 0.05$ \\
Complex II & $1 \pm 0.25$ & $1.17 \pm 0.11$ & $0.71 \pm 0.08$ \\
Complex III & $1 \pm 0.19$ & $1.28 \pm 0.36$ & $0.97 \pm 0.15$ \\
Complex IV & $1 \pm 0.30$ & $1.42 \pm 0.64$ & $1.37 \pm 0.69$ \\
Complex V & $1 \pm 0.35$ & $0.97 \pm 0.18$ & $0.90 \pm 0.13$ \\
Protein & & & \\
Complex I & $1 \pm 0.11$ & $0.61 \pm 0.07 *$ & $0.64 \pm 0.14$ \\
Complex II & $1 \pm 0.10$ & $0.75 \pm 0.20$ & $0.65 \pm 0.13$ \\
Complex III & $1 \pm 0.14$ & $1.23 \pm 0.27$ & $0.54 \pm 0.06^{*}$ \\
Complex IV & $1 \pm 0.10$ & $0.74 \pm 0.17$ & $0.67 \pm 0.11^{*}$ \\
Complex V & $1 \pm 0.09$ & $1.41 \pm 0.26$ & $0.67 \pm 0.06^{*}$ \\
\hline
\end{tabular}

Values are means \pm standard errors of the mean $(\mathrm{n}=5-6$ per group). mRNA expression was normalized to $S 29$ as the housekeeping gene, and protein expression was normalized to $\alpha$-tubulin. $* P<.05$ versus the sham group. 